\title{
Entre a Geometria, as Tecnologias de Representação e o Projeto: Reflexões sobre um Discurso Didático para a Arquitetura
}

Between the Geometry, the Technologies of Representation and the Project:

Reflections on a Didactic Discourse to the Architecture

> Cristiane Nunes

Universidade Federal de Pelotas, Brasil

cristiane.nunes@outlook.com

> Juçara Silva

Universidade Federal de Pelotas, Brasil

arq.jussara@gmail.com
> Adriane Borda

Universidade Federal de Pelotas, Brasil

adribord@hotmail.com

\begin{abstract}
This paper is to contribute to the construction of discourses contextualized, which may explain the confrontation, establish a critical stance toward the design of didactic strategies appropriate to the training in architecture, in their different levels of education.
\end{abstract}

Keywords: Geometry; Design; Technologies of Representation; Didactic Speech.

\section{Introdução}

O cenário de produção arquitetônica analisado especialmente por Pottmann et al (2007) e Burry e Burry (2010) demonstra como o conhecimento da geometria associado às potencialidades atuais das tecnologias digitais de representação tem suportado o exercício da liberdade formal em arquitetura.

Tais cenários têm motivado questionamentos sobre a necessidade de reestruturaçóes curriculares no âmbito do ensino/aprendizagem da arquitetura, principalmente junto à área de representação. Questionam-se quais estruturas do saber devem ser veiculadas para que estudantes construam um repertorio conceitual e procedimental para a compreensão de tal produção arquitetônica. Esta produção está permeada por discursos filosóficos materializados com apoio dos conhecimentos advindos da física e das geometrias complexas. Entretanto, pelo menos no contexto em que se insere este estudo, os conteúdos de matemática e física foram suprimidos da grade curricular. As consequências foram evidenciadas, na área de representação, quando se passou a ter disponíveis, por exemplo, algumas ferramentas de desenho paramétrico, nas quais os parâmetros envolvidos são especificados a partir de modelos matemáticos e físicos. Assim, mesmo na parametrização de geometrias simplificadas, se evidencia a falta de conhecimento prévio dos estudantes.

Referindo-se ainda ao contexto de arquitetura deste trabalho, junto à área de representaçáo, nos últimos anos foram sendo reestruturados os planos de ensino, buscando-se atribuir competências aos estudantes para o reconhecimento das potencialidades das ferramentas digitais para a geração e controle da forma. Em estágios iniciais de formaçáo os estudantes exercitam processos de representação de produções arquitetônicas envolvendo diferentes níveis de complexidade geométrica. Tenta-se avançar no uso de técnicas de desenho paramétrico, demonstrando a possibilidade de conferir à forma arquitetônica uma liberdade escultórica suportada pela precisão matemática. Realizam-se exercícios de materialização destas formas através de processos de prototipagem, utilizando-se de técnicas de corte a laser e de impressão 3D. Este processo de apropriação das tecnologias de representaçáo para o domínio da geometria tem sido acompanhado de um discurso didático dirigido à construção de vocabulário e repertório geométricos prévios à atividade projetual. Entretanto, muitas inquietaçóes vêm sendo formuladas. Apesar de observaçóes positivas das consequências deste investimento junto ao contexto referido, não se estabeleceu uma discussão ampla e interdisciplinar com a área de ensino/aprendizagem de projeto de arquitetura. Alguns professores de projeto expressam a preocupaçáo quanto ao momento de investimento na formação dos estudantes para a apropriaçáo de tecnologias digitais de representaçáo. Alguns afirmam a necessidade de não haver um investimento precoce nos primeiros semestres de formação, exigindo que a representação dos projetos seja totalmente realizada por tecnologias tradicionais. Outros temem a liberdade formal, de investimento em repertórios geométricos que possibilitem o uso indiscriminado de formas complexas especialmente em um momento imaturo de formação para o projeto. Neste contexto, se detecta a necessidade de explicitar e contrapor os discursos advindos destas diferentes abordagens. Isto se faz necessário tanto para o campo da geometria, o qual usufrui 
das potencialidades das tecnologias de representaçáo para habilitar a liberdade formal, como para o campo de projeto, o qual observa as conseqüências junto à ação projetual.

Assim sendo, busca-se contribuir para a construção de discursos contextualizados, os quais possam explicitar tais confrontos, estabelecer uma postura crítica para o desenho de estratégias didáticas apropriadas à formação em arquitetura, nos diferentes níveis de ensino, desde a graduação à pós-graduação.

\section{Materiais e Métodos}

Este estudo está sendo desenvolvido a partir das seguintes etapas: identificação de discursos didáticos sobre o tema, através de revisão bibliográfica; análise dos discursos, buscando-se identificar argumentaçóes convergentes e divergentes sobre o tema; sistematização e difusão dos resultados.

\section{Revisão da Literatura}

Até o momento foram identificados alguns discursos através de revisão bibliográfica. Deve-se destacar que o estudo náo busca identificar discursos que se dirijam a justificar a importância das tecnologias digitais para a atividade de representação arquitetônica, mesmo em seu significado mais amplo, o qual compreende representação como ação projetual propriamente dita. O estudo está centrado em identificar discursos que configurem posturas relativas ao momento e à maneira de inseri-las, considerando-se os contextos das práticas docentes: geometria $\mathrm{x}$ projeto.

Burry e Burry (2010) destacam um conjunto de obras arquitetônicas, as quais foram concebidas sob uma forte estruturação geométrica com o apoio da computação no processo de projeto. Enfatizam as grandes diferenças formais destas obras em relação às outras produzidas no mesmo período sem tal apoio computacional. Tais autores consideram que ocorre esta diferenciação em função do uso de tecnologias digitais e de conceitos geométricos para a concepçáo dos projetos, uma vez que estes permitem que se obtenham resultados surpreendentes.

Alguns dos discursos encontrados, por exemplo, em Mahfuz (2013) e em Lacombe (2013), a partir deste reconhecimento da influência do uso de tecnologias digitais de representaçáo na determinação de formas arquitetônicas complexas, explicitam posturas dirigidas às questôes formativas. Discursos que se contrapóem e pontuam argumentaçôes que fornecem elementos para a construçáo de um discurso didático crítico e contextualizado, transitando entre projeto e representação.

Piñon (2009) em seu artigo faz uma crítica aos processos projetivos que abandonaram a análise formal para concentrar-se na expressão gráfica, cada vez mais assistida pelo computador. Considera que o declínio da importância do desenvolvimento de habilidades de representação gráfica pessoal, presente nos currículos atuais, provoca uma miopia generalizada, verificada com o uso dos recursos digitais de forma pragmática, centrada em seus processos operativos e automatizados.

Na mesma direção, Mahfuz (2013) indica uma crise no ensino de arquitetura com a ausência de critérios para projetar e avaliar arquitetura, baseado nos conceitos chamados por ele de concei- tualismo e digitalismo. Defende que a arquitetura deve nascer da capacidade crítica e de auto-consciência, desenvolvida nos alunos através do estudo crítico das formas e espaços. Para isso, corroborando idéias citadas de Piñon (2009), o ensino de arquitetura deveria passar pela análise, através do 're-desenho' ou atuação direta sobre eles, observando seus elementos e critérios de ordenação, através do que chama '(re)construção gráfica'. Para ambos os autores, tais análises e representaçóes de obras devem ser feitas utilizando-se de referenciais de arquiteturas exemplares. Segundo Mahfuz (2013), o ambiente de formaçáo acadêmica não seria um local adequado para experimentaçóes. E ainda, o autor defende que para tal atividade se utilize apenas obras de arquitetura clássica e moderna, pois somente com estas as chances de encontrar maus exemplos seriam pequenas. Segundo o autor, as obras contemporâneas, com volumetrias diferenciadas que nada tem a ver com a função, mas sim com uma opção do projetista, não possuem valor para serem utilizadas como referências para o ensino.

Mahfuz (2013) também defende o uso das ferramentas digitais para tal processo de representação de arquiteturas, porém, como ferramenta de projeto e não apenas de desenho. Um exemplo de atividade seria o ato de representar as obras, porém simulando alteraçóes de seus programas. Assim, além de reproduzir o que verificou durante as análises da obra, ainda vai aplicar o que aprender criando uma proposta de ampliação seguindo a mesma lógica projetiva do arquiteto.

Por outro lado, Lacombe (2013) rebate os argumentos de Mahfuz (2013). Para ele é inconcebível dizer que as arquiteturas exemplares para estudos formais são somente aquelas do período clássico e moderno. Para ele isso seria ignorar todas as inovaçóes ocorridas na arquitetura desde entâo. Lacombe (2013) ainda defende a arquitetura contemporânea como referencial importante em atividades e análise e representaçáo. Ele argumenta que nunca se utilizou tantos critérios lógicos para a elaboração de projetos como se utiliza na produção contemporânea, em função das novas demandas, tais como as ambientais e tecnológicas.

Além disso, o autor argumenta com veemência que a formação acadêmica deve permitir a experimentação. Para ele, somente aceitar e aprender o que já é consolidado não é o bastante, havendo a necessidade de possibilitar aos estudantes momentos de experimentaçóes, para que possam criar seus próprios métodos de projeto. Para isto, ainda defende as novas tecnologias de representação como meios que permitem tais experimentos.

No trabalho de Oliveira (2009) encontram-se resultados compatíveis com as ideias de Lacombe (2013). O autor fala da necessidade de que o ensino de geometria acompanhe as mudanças na linguagem projetual da arquitetura, que vem ocorrendo com a evolução dos programas de representação gráfica digital. Em seu estudo, o autor levanta a questáo de até aonde chegar com o ensino de geometria em tempos de pleno uso de ferramentas digitais, que facilmente representam até as formas mais complexas. Sua resposta, porém, é de que a questão não deveria ser essa, mas sim a do que mudar no ensino da geometria tendo em vista todo este potencial de ferramentas digitais, já dirigindo-as à esta nova linguagem projetual. 


\section{Resultados e Discussão}

Todos os discursos apresentados devem ser sistematizados e analisados na próxima etapa deste estudo. Entretanto, os resultados parciais mostram a existência de duas vertentes no âmbito da representação para o ensino de arquitetura. Estes podem ser vistos principalmente pelos argumentos de Lacombe (2013) e Mahfuz (2013), os quais abordam as mesmas questóes apresentando ideias contrárias.

\section{Referências}

Burry, J. Burry, M. The New Mathematics of Architecture. New York: Thames \& Hudson.

Lacombe, O. Explorando arquiteturas que se transformam: um breve relato. Drops, São Paulo, ano 13, n. 068.01, Vitruvius. Disponível em: http://www.vitruvius.com.br/revistas/read/ drops /13.068/4733. Acesso em: jun 2014.

Mahfuz, E. Banalidade ou correção: dois modos de ensinar arquitetura e suas consequências. Arquitextos, São Paulo: 2013. Disponível em: http://www.vitruvius.com.br/revistas/read/ arquitextos/ 14.159/4848. Acesso em: jun 2014.

Oliveira, M. Ensino da Geometría Projetiva nos Cursos de Arquitetura e Urbanismo, em tempos de CAD/BIM. In: SIGRADI - Congresso da Sociedade Ibero Americana de Gráfica Digital, São Paulo: 2009.

Piñon, H. Representação Gráfica do edifício e construção visual da arquitetura. Arquitextos, São Paulo:2009. Disponível em: http:// www.vitruvius.com.br/revistas/read/ arquitextos/09.104/81/ pt. Acesso em: ago 2014

Pottmann, A. Asperl, A. Hofer, M. Killian, A. (2007). Architectural geometry. Exton: Bentley Institute Press. 